\title{
Prehospital management of traumatic brain injury
}

\author{
Shirley I. Stiver, M.D., Ph.D., And Geoffrey T. Manley, M.D., Ph.D. \\ Department of Neurosurgery, School of Medicine, University of California San Francisco, California
}

\begin{abstract}
The aim of this study was to review the current protocols of prehospital practice and their impact on outcome in the management of traumatic brain injury. A literature review of the National Library of Medicine encompassing the years 1980 to May 2008 was performed. The primary impact of a head injury sets in motion a cascade of secondary events that can worsen neurological injury and outcome. The goals of care during prehospital triage, stabilization, and transport are to recognize life-threatening raised intracranial pressure and to circumvent cerebral herniation. In that process, prevention of secondary injury and secondary insults is a major determinant of both short- and longterm outcome. Management of brain oxygenation, blood pressure, cerebral perfusion pressure, and raised intracranial pressure in the prehospital setting are discussed. Patient outcomes are dependent upon an organized trauma response system. Dispatch and transport timing, field stabilization, modes of transport, and destination levels of care are addressed. In addition, special considerations for mass casualty and disaster planning are outlined and recommendations are made regarding early response efforts and the ethical impact of aggressive prehospital resuscitation. The most sophisticated of emergency, operative, or intensive care units cannot reverse damage that has been set in motion by suboptimal protocols of triage and resuscitation, either at the injury scene or en route to the hospital. The quality of prehospital care is a major determinant of long-term outcome for patients with traumatic brain injury.
\end{abstract}

(DOI: $10.3171 /$ FOC.2008.25.10.E5)

KEY WoRDS • hypotension • hypoxia $\quad$ intracranial hypertension
outcome assessment

$\mathrm{T}$ Ireatment of patients with TBI begins at the time of impact. By its nature, trauma demands focused attention on the most paramount life-threatening problems. Less urgent problems are relegated to a lesser priority. However, less urgent does not necessarily equate with less important. We performed a literature search of the National Library of Medicine encompassing the years 1980 to May 2008 using search terms pertinent to prehospital care, emergency triage, trauma system organization, and brain injury. The goal of this review was to evaluate the critical role that prehospital management plays in the pathophysiology and outcome of TBI. By the time the patient is in the emergency department, the damage of primary injury has made its mark and the processes of secondary injury have been set in motion. The quality of the care rendered in the prehospital setting is as important, if not more important, than the time taken to

\footnotetext{
Abbreviations used in this paper: $\mathrm{CBF}=$ cerebral blood flow; $\mathrm{CPP}=$ cerebral perfusion pressure; GCS = Glasgow Coma Scale; $\mathrm{ICP}=$ intracranial pressure; $\mathrm{OR}=$ odds ratio; $\mathrm{RSI}=$ rapid sequence intubation; TBI = traumatic brain injury.
}

reach definitive treatment. The key goals of the emergency response team are to stabilize and treat damage from the primary injury, to abrogate or minimize secondary injury, and to prevent secondary insults at all costs. With comparatively few available resources, care in the field (prehospital setting) is a critical determinant of outcome for patients with TBI.

\section{Epidemiology}

In the US every year, 1.4 million people sustain a TBI. Trauma is the leading cause of death and disability in children and young adults, and TBI accounts for approximately 52,000 (or one-third) of all deaths. ${ }^{148}$ Roughly twice this number suffer permanent neurological deficits. The severity of TBI is categorized based on the GCS score. Severe TBI (GCS Scores from 3 to 8) comprises approximately $10 \%$ of TBI, moderate head injury (GCS scores from 9 to 12) comprise approximately another $10 \%$, and the vast majority of TBI $(\sim 80 \%)$ is classified as mild head injury, presenting with a GCS Score ranging from 13 to $15 .^{78}$ In the last 30 years, dedicated trauma programs have demonstrated that aggressive prehospital programs reduce morbidity and death from TBI. ${ }^{1,7,9,61,82}$ 


\section{Mechanisms of Injury}

An understanding of the pathophysiological mechanisms of primary and secondary injury are crucial to setting optimal protocols of care to enable further advances in the outcome of patients with TBI. Primary injury occurs at the time of impact and is not reversible. Direct damage involves contact energy transfer and inertia energy transfer. In addition to these mechanical forces to the brain itself, primary injury also occurs to the cerebral vasculature leading to vessel shear and disruption. Secondary injury evolves as a cascade of cellular events that are set in motion at the time of the primary impact. Within the first hours after injury a complex array of inflammatory, excitotoxic, oxidative stress, metabolic, vascular, and mitochondrial mechanisms have been activated and each has progressed to initiate further injury. The various components of secondary injury interact with each other in a multiplicative rather than additive fashion. Secondary injury is a direct consequence of the primary impact, whereas secondary insults are discrete processes, often iatrogenic, that occur independently of the primary impact. Improved outcomes following aggressive treatment of mass lesions, hypoxia, hypotension, and fluid and electrolyte abnormalities have shown that secondary events following TBI are preventable and treatable. ${ }^{160}$

\section{Prevention of Secondary Injury in the Prehospital and Emergency Setting}

Increased ICP, cerebral edema, cerebral dysautoregulation, and alterations in brain metabolism are inherent sequelae of the primary brain injury. Exogenous or iatrogenic events exacerbate these secondary injury processes. Patients with multiple traumas frequently incur injuries that compromise cardiopulmonary status, and they are therefore particularly vulnerable to secondary injury. Secondary insults are common and are independent predictors of poor outcome in patients with TBI. $28,47,102$ Depth and duration of hypotension, but not hypoxia, has been shown to trend in a dose-response manner with the 3-month functional Glasgow Outcome Scale score. ${ }^{6}$ In contrast, hypoxia and hypotension do not have nearly as profound an effect on outcome in patients with extracranial trauma. The prehospital guidelines were developed by the Brain Trauma Foundation (www.braintrauma.org) to standardize acute TBI care and prevent secondary injuries and insults. ${ }^{19,59,146}$ Implementation of these guidelines with prevention and treatment of secondary injury in the early phases of care significantly improves patient outcomes following severe TBI. ${ }^{160}$

\section{Brain Oxygenation}

Airway obstruction and aspiration are major causes of death in patients who die of treatable head injuries. ${ }^{149}$ Under normal physiological circumstances, the brain is dependent on aerobic metabolism to maintain the high adenosine triphosphate requirements of neuronal function, and energy failure occurs after a few minutes of anaerobic metabolism. ${ }^{104,138}$ Apnea, even for just a brief period, accompanies most head injuries. ${ }^{47,103}$ In response to hypoxia, a compensatory increase in CBF occurs, but not until the partial pressure of $\mathrm{O}_{2}$ drops to $<50 \mathrm{~mm}$ Hg. ${ }^{50,86,101}$ Results from the Trauma Coma Data Bank showed that a low $\mathrm{PaO}_{2}(\leq 60 \mathrm{~mm} \mathrm{Hg})$ occurred in $46 \%$ of 717 admissions to the emergency department. ${ }^{26}$ Arterial desaturations to this degree, even for a short time, were associated with a $50 \%$ mortality rate and $50 \%$ severe disability among survivors. ${ }^{143}$ Multiple studies have confirmed that a low $\mathrm{PaO}_{2}(<60 \mathrm{~mm} \mathrm{Hg})$ correlates with worsened patient outcomes. $23,28,104,156$

Although airway control is intuitively important, a few studies have unexpectedly reported worse outcomes for patients with TBI who were intubated in the field. . $^{14,33,37,41,53,110,158}$ In the field, hypoxia is defined as apnea, cyanosis, an $\mathrm{O}_{2}$ saturation $<90 \%$, or a $\mathrm{PaO}_{2}<60 \mathrm{~mm}$ $\mathrm{Hg}$. Marked degrees of hypoxia to saturations $<70 \%$ are common during intubation with $57 \%$ of patients experiencing transient hypoxia lasting a mean of 2.3 minutes..$^{51}$ The risk of desaturation associated with intubation is dependent on the starting $\mathrm{O}_{2}$ saturation and occurs $100 \%$ of the time if the $\mathrm{O}_{2}$ saturation is $\leq 93 \%$, versus $6 \%$ if it is $>93 \%(\mathrm{p}<0.01) .{ }^{38} \mathrm{~A}$ comparison of 1797 patients with severe TBI who were intubated in the prehospital setting with 2301 patients who were intubated in the emergency department demonstrated a 4-fold increase in death and a significantly higher risk of poor neurological and functional outcome in the group of patients who were intubated in the field. ${ }^{158}$

Endotracheal intubation is associated with risks of increased ICP, aspiration, and hypoxia. The detrimental effects of aspiration or hypoxia before arrival of the emergency response team may not be reversible. ${ }^{38}$ Positive pressure ventilation can increase intrathoracic pressure, which may decrease venous return, and in a hypovolemic patient this can impair CPP. Furthermore, sedative agents used during RSI can cause hypotension. ${ }^{39}$ Prehospital intubation may also delay transport. Importantly, endotracheal intubation in the field predisposes the patient to an increased incidence of overly aggressive hyperventilation that has been shown to adversely affect outcome $^{34,36,110} \mathrm{~A}$ series of 851 patients with TBI, prehospital intubation, and a range of $\mathrm{PCO}_{2}$ levels on arrival to the emergency department $\left(17 \%, \mathrm{PCO}_{2}<30 ; 47 \%, \mathrm{PCO}_{2}\right.$ $30-39$; and 26\%, $\mathrm{PCO}_{2}>40$ ) were divided into 2 groups. Those within the target $\mathrm{PCO}_{2}$ range of 30-39 had a mortality rate of $21 \%$, whereas those whose $\mathrm{PCO}_{2}$ persistently remained outside the target range experienced a mortality rate of 34\%. ${ }^{159} \mathrm{With}$ increasing head severity, there was an increased survival benefit for patients who attained their goal $\mathrm{PCO}_{2}$ level.

Airway management and the prevention of hypoxia is a priority. ${ }^{20}$ All patients should receive supplemental $\mathrm{O}_{2}$ to maintain saturations $>90 \%$. In the prehospital setting, intubation has been a mainstay procedure in the treatment of patients with severe TBI and GCS scores $\leq 8$, both for maintenance of good oxygenation and prevention of aspiration. The prehospital guidelines of the Brain Trauma Foundation recommend that unconscious or unresponsive patients with GCS scores $\leq 8$ or those unable to maintain an adequate airway, and those with hypoxemia (arterial $\mathrm{O}_{2}$ saturation $<90 \%$ ) despite supplemental 
$\mathrm{O}_{2}$, should be intubated. In the prehospital setting of a comatose patient with a head injury, orotracheal intubation is preferred over nasotracheal intubation because the status of possible basal skull fractures is unknown and noxious stimulation of the nares can elevate ICP. Intubation not only enables adequate oxygenation, but can also alleviate hypercarbia that itself can worsen ICP. In the absence of signs of raised ICP, patients should not undergo hyperventilation prophylactically.

A consensus panel has addressed the question of poorer outcomes in prehospital patients with TBI who have been intubated. This panel found no prospective controlled trials to adequately address the efficacy of paramedic RSI for severe TBI. ${ }^{35}$ Concerns were raised regarding the use of a GCS score alone to identify patients who warrant intubation. ${ }^{43}$ The GCS score provides no information as to patient oxygenation status and there is poor interobserver reliability for this score. ${ }^{8,65}$ Furthermore, the force of the impact is often sufficient to induce a ventilatory pause, the duration of which is proportional to the force, and early assessments of GCS scores immediately after injury may be inaccurate. The consensus panel suggested that other factors and methods such as pulse oximetry and transport time be incorporated, in addition to the GCS score, to define candidates for intubation. ${ }^{35}$ Pulse oximetry and capnometry were recommended for monitoring depth of sedation during conscious sedation. Importantly, success of intubation with RSI does not alone improve outcome. ${ }^{37,42}$ The continued treatment of the ventilated patient with careful monitoring of end-tidal $\mathrm{CO}_{2}$ and prevention of hyperventilation is paramount to achieving improved outcomes in the field. ${ }^{36,122}$

\section{Hypotension}

Numerous studies have shown a significant association between hypotension and poor outcome in patients with head injuries. ${ }^{16,26,27,56,92,95,111,132,143,156}$ In a study of 613 patients from the Traumatic Coma Data Bank, a single episode of hypotension (systolic blood pressure < $90 \mathrm{~mm} \mathrm{Hg}$ ) in the field doubled the mortality rate..$^{27,120}$ Estimates suggest that $8-13 \%$ of patients with severe head injuries are hypotensive at the injury scene or in the emergency department. ${ }^{26}$ Isolated head injury does not cause hypotension. The brain's ability to extract $\mathrm{O}_{2}$ protects it from hypoxia as long as cerebral perfusion is maintained. ${ }^{26}$ In accordance with this concept, hypotension has been reported to be a stronger predictor of poor outcome than hypoxia. ${ }^{6,26}$ Cerebral ischemia is evident in the vast majority of patients who die of head injury. ${ }^{66}$ Secondary ischemia is a manifestation of the loss of autoregulation and is more common and more severe with increasing severity of brain injury. ${ }^{25,95,99}$ In the absence of intact autoregulation, brain perfusion becomes passively dependent on the systemic blood pressure and hypotension leads to hypoperfusion and brain ischemia. Furthermore, in experimental animal models, mechanical injury decreases the threshold for ischemic damage and neuronal loss. ${ }^{77}$ Low CBFs are frequent in the early hours following head injury, and even in the absence of blood loss a brief hypotensive episode can initiate irreversible cell death mechanisms in injured neurons. ${ }^{116}$
Despite the strong association between poor outcome and hypotension in patients with head injuries, the general trauma literature has questioned the value of time spent securing intravenous access and administering fluids in the field. ${ }^{87,131}$ It has been argued that obtaining intravenous access is time-consuming and the small volumes infused during short transports may not significantly affect outcome. ${ }^{139}$ Arguments in favor of delayed resuscitation with "permissive hypotension" include reports that administration of intravenous fluids to actively bleeding patients, before definitive surgical control, may increase blood loss because of hemodilution, higher blood pressures, impaired thrombus formation, and clot disruption. ${ }^{12,117}$ For patients with severe head injuries, delayed fluid resuscitation risks significant secondary injury that occurs when CPP falls. . $^{17,124,125}$ Patients with head injuries treated with delayed resuscitation have been shown to experience progressive intracerebral swelling and increased ICP, as well as higher lactate/pyruvate ratios as a result of delayed restoration of $\mathrm{CBF}^{2}{ }^{2}$

Management of hypotension in the field improves outcome for patients with severe TBI. ${ }^{64,150}$ In children, systolic pressure goals are lowered in an age-dependent manner. ${ }^{83}$ Intravenous fluids should be administered to avoid hypotension or to minimize the duration and extent of hypotension. The scalp has a rich blood supply and scalp lacerations should be addressed as a treatable cause of hypotension. Excessive bleeding consumes coagulation factors and platelets. Administration of intravenous fluids in the setting of excessive bleeding may further worsen coagulopathy through mechanisms of dilution of clotting factors and platelets, hyperchloremia leading to acidosis, hypocalcemia, and hypothermia. ${ }^{58}$

The optimal fluid for resuscitation has not been clearly determined. Intravenous fluids should be isotonic to reduce brain swelling and cerebral edema. Normal saline is preferred over lactated Ringer solution, and solutions containing 5\% dextrose (D5W) should be rigorously avoided. Hypertonic saline expands intravascular volume by 4 - to 10 -fold that of the volume infused ${ }^{49}$ Hypertonic saline provides the potential benefit of enabling blood pressure stabilization with smaller volumes. It supports CPP without aggravating leakage and extravascular fluid accumulation that leads to cerebral edema and increased ICP, which occurs following infusion of high volumes of isotonic fluids. ${ }^{48}$ Hypertonic saline also acts in a fashion similar to mannitol and induces an osmotic diuresis that assists treatment of raised ICP. Resuscitation with hypertonic saline doubles the survival rate of patients with TBI who present with hemorrhagic shock. ${ }^{151,155}$ In subgroup analyses, patients with TBI and GCS scores $\leq 8$ are most likely to benefit from hypertonic saline. ${ }^{150,152}$ However, studies have yet to demonstrate an improvement in longterm neurological outcomes for patients with head injuries resuscitated using hypertonic saline. ${ }^{31}$ A prospective intervention trial is planned to compare hypertonic saline, hypertonic saline with dextran $6 \%$, and normal saline in a subgroup of patients with TBI and GCS scores $\leq 8$, both with and without hypovolemic shock (systolic blood pressure $\leq 90 \mathrm{~mm} \mathrm{Hg}){ }^{18}$ 


\section{Management of Suspected Raised ICP}

The motor component of the GCS score is the most informative measure of the score for long-term outcome..$^{29,47,97}$ Hypoxemia and hypotension can lower a patient's GCS score, and thus assessments made following resuscitation are more reliable. ${ }^{94}$ If possible, a GCS score prior to administration of sedative or paralytic agents serves as a valuable baseline. Serial examinations are important. A drop of 2 or more points in the GCS score is considered significant and should raise an index of suspicion for an expanding intracranial mass lesion. ${ }^{135}$ In a series of 81 patients with initial field GCS scores of 13 or 14 who subsequently deteriorated and required prehospital intubation, $31 \%$ had an abnormal CT scan and $21 \%$ had evidence of an intracranial hemorrhage. ${ }^{54}$ The development of an oval or irregular pupil is the first sign of uncal herniation. ${ }^{98}$ Signs of cerebral herniation also include asymmetric pupils with a difference $>1 \mathrm{~mm}$ in size, unilateral or bilateral dilated and fixed pupils, extensor (decerebrate) posturing, or a progressive loss of 2 points in GCS score starting from an initial GCS score $\leq 8$.

In the setting of signs of cerebral herniation, urgent measures are needed to lower ICP. These measures should include acute hyperventilation and mannitol administration. ${ }^{154}$ In addition, good outcomes for patients with traumatic intracerebral mass lesions correlate strongly with prompt surgical evacuation. ${ }^{72,121,133,144}$ In the face of a declining GCS score, the prime goal should be definitive neurosurgical care. In these situations, timing becomes critical as outcome directly correlates with the duration of the mass effect.

Mannitol Administration. The mechanisms underlying the therapeutic benefits of mannitol are not thoroughly understood. By increasing the osmotic gradient between blood and the brain, water is drawn from normal and edematous brain into the vascular compartment, leading to prompt osmotic diuresis and a reduction in ICP. ${ }^{76,161}$ The onset of action is within 15-30 minutes with a peak response at 1 hour, lasting for 6-8 hours. ${ }^{5}$ Mannitol is more effective when given in a high dose $(1.4 \mathrm{gm} / \mathrm{kg})$ as a bolus rather than by continuous infusion. ${ }^{21,32,142}$ Mannitol also reduces blood viscosity and improves the rheology of blood flow. ${ }^{24}$ There is evidence to suggest that mannitol also acts through vasoconstriction in response to these changes in blood viscosity. ${ }^{106,108}$

Hypertonic Saline. Hypertonic saline has been shown to be as effective as mannitol in treating raised ICP in patients with head trauma. ${ }^{48,57,112}$ Concentrations ranging from $7.5 \%(2 \mathrm{mg} / \mathrm{Kg})$ to $23 \%$ (1 ampule, $30 \mathrm{ml})$ are effective. ${ }^{71,145,154,162}$ Hypertonic saline acts through osmotic, vasodilatory, hemodynamic, antiinflammatory, and neurochemical mechanisms. ${ }^{48}$ Through osmotic effects, hypertonic saline draws fluid into the intravascular compartment, reducing brain water and improving perfusion. In both human and animal studies, hypertonic saline has been shown to increase mean arterial pressure, likely as a result of plasma volume expansion. ${ }^{48}$ Problems of volume depletion and hypotension are not as profound with hypertonic saline as they are with mannitol. ${ }^{71,109,114,153}$
Hyperventilation Therapy. Moderate hyperventilation therapy is indicated as a temporizing, life-saving intervention for the comatose patient with impending cerebral herniation. Carbon dioxide is a potent vasodilator of the cerebral microcirculation. For every $1 \mathrm{~mm} \mathrm{Hg}$ drop in $\mathrm{PCO}_{2}$ there is a concomitant $3 \%$ decrease in $\mathrm{CBF}^{15} \mathrm{Hy}-$ perventilation quickly decreases cerebral arteriolar diameter and can dangerously lower CBF. ${ }^{96,111}$ Microdialysis and brain tissue $\mathrm{O}_{2}$ measurements have demonstrated that even brief periods of hyperventilation can lead to hypoxia and clinically significant changes in metabolites, together, indicative of cerebral ischemia..$^{93,96}$ The potential for hyperventilation to compromise $\mathrm{CBF}$ is especially true in the early phases of severe brain injury when autoregulation is impaired and $\mathrm{CBF}$ is reduced from the injury itself. $^{95,107,137}$ Ventilatory interventions to hyperventilate the patient frequently also alter thoracic pressures and may have deleterious effects by decreasing venous return and raising ICP. For these reasons, hyperventilation should be reserved for situations of acutely increased ICP with impending cerebral herniation. ${ }^{22}$

Without clear evidence of cerebral herniation, $\mathrm{pCO}_{2}$ goal values in the prehospital setting should be in the range of 35 and $40 \mathrm{~mm} \mathrm{Hg}$, typically achieved with tidal volumes of $10 \mathrm{ml} / \mathrm{kg}$ and ventilatory rates of 10 breaths/ minute. ${ }^{74}$ Herniating patients should be hyperventilated to $\mathrm{PCO}_{2}$ levels not $<30 \mathrm{~mm} \mathrm{Hg}$, with a goal of 30-35 $\mathrm{mm} \mathrm{Hg}$. End-tidal $\mathrm{PCO}_{2}$ may not be a reliable measure of $\mathrm{PaCO}_{2}$, particularly in patients with multiple traumas, chest injuries, hypovolemia, and hypotension secondary to massive blood loss. ${ }^{11,74,134}$ In practice, studies continue to show a relative disparity between the guidelines and clinical practice. ${ }^{147,159}$ Manual ventilation, with high ventilatory assist rates, appears to predispose the patient to low end-tidal $\mathrm{CO}_{2}$ levels. ${ }^{147}$

\section{Temperature}

Hypothermia is a predictor of death in trauma patients. ${ }^{80,89}$ A retrospective analysis of 38,520 trauma patients, aged $\geq 16$ years with an admission body temperature $\leq 35^{\circ} \mathrm{C}$, demonstrated an increased risk of death in all patients (OR 3.03, 95\% confidence interval 2.6-3.5) as well as in a subgroup of patients with isolated, severe TBI (OR 2.21, 95\% confidence interval 1.6-3.0). ${ }^{157}$ In experimental models, induced hypothermia has several physiological actions beneficial to TBI. Hypothermia acts on the central nervous system to decrease metabolism, and for every $1{ }^{\circ} \mathrm{C}$ drop in temperature there is a $6-7 \%$ decrease in the cerebral metabolic rate for $\mathrm{O}_{2} \cdot{ }^{55,126}$ The results of several good quality meta-analyses showed a benefit to induced therapeutic hypothermia for severe TBI, but failed to demonstrate statistical improvements in long-term clinical outcome. ${ }^{119}$ During induced therapeutic hypothermia, shivering and catecholamine responses are controlled and the pathophysiological mechanisms may differ from those occurring in spontaneous exposure hypothermia, wherein stress responses proceed unabated. Further, the duration of induced hypothermia is usually 24-48 hours or longer as compared with the relatively short periods for field hypothermia. Rebound increases in ICP may also occur during rewarming. ${ }^{13}$ However, early 
spontaneous hypothermia, such as that which occurs with field hypothermia, may be effective in minimizing brain injury if patients are not rewarmed. Young patients $<45$ years of age who present with hypothermia $\left(<35^{\circ} \mathrm{C}\right)$ experienced a statistically higher incidence of better ICP control and a lower incidence of poor outcome (76\%) if they were kept hypothermic $\left(33^{\circ} \mathrm{C}\right)$ for 48 hours, as compared with those who were warmed on admission. ${ }^{30,90}$

\section{Organized Emergency Trauma Systems}

\section{Dispatch and Triage Planning}

Optimal treatment of patients with TBI begins with the 911 call and efforts to acquire information regarding the possibility of TBI, to thereby dispatch the most appropriate team of providers to the scene. The level of skill of the response team and the time to reach the hospital strongly influence the efforts to stabilize the patient in the field. There appears to be a threshold set of skills necessary to prevent secondary injury, above which further abilities appear to be less important. Technical facility with airway management, securing intravenous access, and the ability to administer mannitol would appear advantageous to modern aggressive response efforts to prevent secondary injury from hypoxia, hypotension, and cerebral herniation in the prehospital setting. The response care team needs to integrate the mechanism of injury, the location of and duration to the hospital, the patient's neurological examination, the involvement of other lifethreatening extracranial injuries, and the potential for further deterioration. A rapid decision is made, balancing further efforts in the field against direct transport of the patient. The degree to which the patient is stable and/ or can be stabilized in the field guides whether the patient should be transported to a Level I or regional trauma center as compared with the closest medical center with emergency services.

In the field, an assessment of the severity of the head injury determines the need for field intervention and stabilization. The emergency response team needs to perform repeated neurological examinations. Patients with TBI require special attention to signs of cerebral herniation that indicate a mass lesion. A unilateral dilated pupil in a comatose patient is the hallmark sign, a warning signal of a possible expanding hematoma. This sign should prompt the highest priority for urgent transport to a center capable of providing definitive neurosurgical care. Secondary injury is more commonly associated with severe as compared with mild or moderate TBI. A degree of hypoxia or hypotension may be tolerated without sequelae in a patient with mild head injury. The same insult in a patient with severe TBI can result in irreversible neuronal injury and permanent deficit. Difficult extrications threaten survival and dramatically increase the risk of secondary injury following TBI. In a similar fashion, associated extracranial injuries may increase the risk of subsequent secondary events from profound or prolonged hypotension. In preparation for air flight, assessment of thoracic and cranial injuries is critical. Open depressed fractures, fractures into the air sinuses, and signs of basal skull fracture may be indicators of underlying intracranial pneumocephalus and should increase awareness for possible complications from expansion of the air collection and/or development of tension pneumocephalus during transport at elevated altitudes. During triage in the field, the response team must identify the patients with a potential risk for deterioration and integrate this risk into field stabilization efforts, mode of transport, and transport destination decisions.

\section{Timing of Treatment}

The merits of prehospital stabilization versus the need for prompt transport to definitive care need to be tailored to each individual patient. ${ }^{87}$ The "golden hour" principle guides prehospital response teams to get the patient to their destination center so that they are able to receive surgery within the 1 st hour of the injury. ${ }^{85}$ In the general trauma literature, studies comparing advanced life support versus basic life support have supported a "scoop and run" approach and this philosophy has been widely adopted. ${ }^{113}$ However, whereas insults such as hypotension or hypoxia may be tolerated for a period of time in a trauma patient with a mild head injury, these same insults can be highly detrimental to a patient with a severely injured brain. For patients with severe TBI, better survival rates and long-term outcomes are achieved with on-scene stabilization in the field. ${ }^{44,63}$

Organized trauma systems improve patient out-

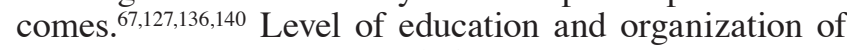
trauma response teams may influence adverse events more so than geography and speed. Several studies have documented that critical care teams composed of physicians and trained nurses achieve better outcomes for patients with severe TBI. ${ }^{1,7,61,62,115}$ Even though critical care response teams incur longer median prehospital times than typical response teams (113 vs 45 minutes, respectively; $\mathrm{p}<0.001)$, these increases were not an independent predictor of outcome. ${ }^{61}$ Urgent transport following stabilization is, however, a priority for patients with mass lesions and impending cerebral herniation. For acute subdural hematomas, the mortality rate increases to $90 \%$ if surgical evacuation is delayed 4 hours or more after injury, as compared with a mortality rate of $30 \%$ if evacuation occurs sooner. ${ }^{133}$ There is evidence from early studies to suggest that within a 4-hour time window, duration of transport has a relatively small influence on outcome. ${ }^{46,88}$ Together these data suggest that on-scene stabilization and the quality of care in the field is as important as speed in improving outcomes following severe TBI. ${ }^{744}$

\section{Mode of Transport}

Most dispatch decisions focus on estimated time or distance for ground transport to reach the target receiving hospital, and a threshold leads to the decision to request aeromedical transport. Odds of survival (1.6-2.25) are better following helicopter as compared with ground transport and it is the patients with severe TBI who benefit the most from air transport. ${ }^{40}$ Reasons for this benefit may include the presence of ancillary nurse or physician members on the response team, careful attention to postin- 
tubation ventilatory parameters with close monitoring of end-tidal $\mathrm{CO}_{2}$, and a transport destination to a definitive Level I or regionalized trauma center. ${ }^{35,122}$ Furthermore, at the receiving hospital $46 \%$ of patients brought in by the aeromedical team had CT performed immediately upon arrival, as compared with only $3 \%$ of those transported by land emergency medical services.

There is an expected but unpredictable drop in barometric pressure with rapid altitude ascent. An average drop in $\mathrm{O}_{2}$ saturation of $4 \%$ has been found in healthy passengers seated in air cabins at altitudes of 8000 feet. ${ }^{105}$ Stable oxygenation can be achieved during air flight transport and mechanical ventilation. In studies from Iraq, 22 patients requiring mechanical ventilation were continuously monitored during transport from Balad to Germany, with an average flight time of 6-8 hours at altitudes of 37,000 feet. ${ }^{4}$ There were 3 desaturation events (saturation of peripheral $\mathrm{O}_{2}<90 \%$ ), the longest lasting 280 seconds, and each resolved spontaneously without intervention.

\section{Transport Destination}

The choice of final destination for transport of patients with head injuries is an important component in prehospital management of TBI. Rapid transport to a center with round-the-clock neurosurgical expertise is probably the single most important determinant of outcome in patients with mass lesions. ${ }^{72,133}$ Lower mortality rates for patients with TBI occur in those transferred to a Level I trauma facility as compared with those treated in a Level II center $(p=0.017) .{ }^{100}$ Significant delay and worse outcome generally occurs if a patient with head injury is transported first to a local hospital for hemodynamic stabilization and then requires transfer to another hospital for neurosurgical management of their intracranial injury. ${ }^{45,70,121,128,130,163}$ Even after stabilization at the original hospital, Dunn et al. ${ }^{52}$ found a $6 \%$ incidence of hypoxia (saturation $<95 \%$ ) and a $16 \%$ incidence of hypotension (systolic blood pressure $<90 \mathrm{~mm} \mathrm{Hg}$ ) upon arrival at the transfer receiving hospital. Treatment volume of the center also influences outcomes for patients with severe TBI. A higher risk of death occurs in low-volume trauma centers, ${ }^{141}$ and advanced trauma centers report a one-third reduction of deaths due to head injuries, as compared with hospitals without a dedicated trauma center. ${ }^{68}$

All regions should have an organized trauma system and protocols to guide field stabilization, timing of transport, and choice of destination. In general, patients with a GCS score of 14 or 15 should be transported to the nearest emergency department. Patients with GCS scores of 9-13 have a potential need for neurosurgical intervention and should be transported to a trauma center. Patients with severe head injuries (GCS Scores from 3 to 8) who can be stabilized at the scene or en route should be transported to a center with neurosurgical expertise and specialized TBI capabilities. Proponents of regionalized trauma centers exalt the benefits of high quality, standardized care for all patients with TBI in these centers. ${ }^{69,75,91}$ Hannan et al. ${ }^{69}$ reported an OR of $0.53-0.85$ for death in patients with TBI treated at a regionalized trauma center as compared with care at other hospitals.

Special transport considerations pertain to the pedi- atric population. In general, pediatric patients with severe TBI are best treated in a pediatric trauma center or in an adult trauma center with qualifications for managing children. Direct transport, rather than transport to a temporizing facility and delayed transfer to a definitive pediatric trauma center, also leads to improved survival and better outcomes in pediatric patients with severe TBI. ${ }^{79}$ Pediatric patients with severe TBI have poorer survival rates if they are treated at Level II adult trauma centers. ${ }^{123}$

\section{Disaster and Mass Casualty Events}

Recent world events, political and natural, have heightened the awareness and need for prehospital care of the highest standards for mass casualty events. The levels of trauma care in the Iraq war are a model for mass casualty and disaster trauma programs. ${ }^{3}$ In Iraq there are 5 levels of care -3 in the combat zone, 2 outside the combat zone. In the combat zone, levels of care progress from first aid in battle (Level I), to mobile resuscitation surgical teams supporting combatant units in the field (Level II), to hospitals that provide advanced care similar to the level of a civilian trauma center (Level III). Definitive neurosurgical care and CT scanners are available at Level III centers, which are typically 15-45 minutes away by air transport. Level IV care is provided outside the combat zone and Level $\mathrm{V}$ care is provided at a center in the US.

High-energy mechanisms are involved in many disaster and mass casualty situations. Blast injuries have been the signature injury of the Iraq war. ${ }^{60}$ Hypotension and profound near-exsanguination levels of hemorrhage are common. Operation Iraqi Freedom and evaluation of casualties from previous wars have shown that exsanguinations from extremity trauma can be prevented with prehospital tourniquets with little risk to limb survival if tourniquet times are $<6$ hours..$^{10}$ With the potential for serious lung injury, massive transfusions, and higher incidences of adult respiratory distress syndrome, the availability of adequate $\mathrm{O}_{2}$ supplies may be a limiting resource and mass casualty planning needs to prepare for this eventuality. ${ }^{4}$ Critical care air transport teams need to be able to mobilize quickly. Drugs typically used in the prehospital setting need special storage as they may be detrimentally affected by the extremes in temperature that frequently prevail in these situations. ${ }^{73}$ In addition, increased awareness of the importance of preventative injury for the emergency response team needs to be a priority. Of 282 patients hospitalized following the 911 World Trade Center terrorist attack, 35 cases of TBI were identified, onethird of these occurring in the rescue workers. ${ }^{129}$

Secondary injury and insults are often underappreciated in crises, and this risk is even more likely during mass casualty care. In a mass casualty crisis, nonneurosurgeon caregivers may be faced with management of severe TBI including penetrating injuries to the cranium. Inexperienced response persons, while trying their best, may inadvertently cause injuries that lower the normally accepted standards of care. The sensitivity of the injured neuron to secondary insults makes patients with TBI more vulnerable in the setting of mass casualty. Closed-loop control systems that use feedback mechanisms to deter- 
mine the dynamic output and maintain parameters within preset goals are being introduced in many technological aspects of trauma and critical care. ${ }^{118}$ These new strategies may help maintain the high standards of prehospital care needed for TBI casualties.

\section{Ethical Considerations}

Studies have demonstrated that it is very difficult to accurately predict prognosis within the first 24 hours of TBI. ${ }^{81}$ Aggressive resuscitation efforts in the acute phases of TBI decrease mortality rates. More controversial is the question of whether these resuscitation efforts improve the number of patients with good outcome or whether they increase the number of survivors with vegetative and disabled outcomes. Patients with very severe head injuries generally die regardless of the speed, intensity, and quality of prehospital care. ${ }^{84,113}$ In a study of accidental fatalities, approximately one-half of all patients died within the first minutes after injury. ${ }^{149}$ In one-third of casualties, death occurred in the first few hours following injury, and brain injury and hemorrhage were found to be the principal causes of death. ${ }^{149}$ With the intervention of air medical and rapid-response teams, patients with minimal residual neurological functions (GCS scores of 4) have shown the greatest increase in survival. ${ }^{40}$ In contrast, patients with a GCS score of 3 did not fare better with aeromedical response teams, suggesting that these patients have suffered irreversible damage from their injuries that is not salvageable, no matter how quickly emergency personnel arrive on the scene or how quickly the injured are transported to a hospital. ${ }^{7}$ Longer transport times allow for severely injured patients with devastating primary injury to declare themselves as casualties. Unresponsiveness from the moment of impact, accompanying cardiac arrest in the field with hypoxia and hypotension, together with short transport times to the hospital are risk factors for persistent vegetative outcomes. It is important for emergency response teams to critically evaluate the best neurological examination of the patient in the field. This examination serves as a marker for the degree of primary injury and aids resuscitation efforts in these difficult situations. In the acute setting, the goals of the prehospital care team should be to do everything possible to stabilize the patient and prevent secondary injury. In this time frame, it is too early, even in the most dismal of situations, to prognosticate patient outcome. Assessments of medical futility and possible organ donation are best delayed until sufficient time has allowed the results of resuscitative efforts to be carefully evaluated.

\section{Conclusions}

The goals of prehospital care for TBI are to stabilize patients for transport, to triage those with mass lesions and impending cerebral herniation, and to prevent secondary insults and injury. Organized trauma systems with defined protocols for field resuscitation, modes of transport, and trauma facility destination ensure reproducible high-quality prehospital care. Given the proximity to the time of impact, advances in prehospital practice are a key target for further improvements in long-term functional outcomes following TBI.

\section{Disclaimer}

The authors report no conflict of interest concerning the materials or methods used in this study or the findings specified in this paper.

\section{References}

1. Abbott D, Brauer K, Hutton K, Rosen P: Aggressive out-ofhospital treatment regimen for severe closed head injury in patients undergoing air medical transport. Air Med J 17:94100, 1998

2. Alspaugh DM, Sartorelli K, Shackford SR, Okum EJ, Buckingham S, Osler T: Prehospital resuscitation with phenylephrine in uncontrolled hemorrhagic shock and brain injury. J Trauma 48:851-854, 2000

3. Bagg MR, Covey DC: Powell ET: Levels of medical care in the global war on terrorism. J Am Acad Orthop Surg 14:S7S9, 2006

4. Barnes SL, Branson R, Gallo LA, Beck G, Johannigman JA: En-route care in the air: snapshot of mechanical ventilation at 37,000 feet. J Trauma 64 (2 Suppl):S129-S135, 2008

5. Barry KG, Berman AR: Mannitol infusion. III. The acute effect of the intravenous infusion of mannitol on blood and plasma volumes. N Engl J Med 264:1085-1088, 1961

6. Barton CW, Hemphill JC, Morabito D, Manley G: A novel method of evaluating the impact of secondary brain insults on functional outcomes in traumatic brain-injured patients. Acad Emerg Med 12:1-6, 2005

7. Baxt WG, Moody P: The impact of advanced prehospital emergency care on the mortality of severely brain-injured patients. J Trauma 27:365-369, 1987

8. Bazarian JJ, Eirich MA, Salhanick SD: The relationship between pre-hospital and emergency department Glasgow coma scale scores. Brain Inj 17:553-560, 2003

9. Becker DP, Miller JD, Ward JD, Greenberg RP, Young HF, Sakalas R: The outcome from severe head injury with early diagnosis and intensive management. J Neurosurg 47:491502,1977

10. Beekley AC, Sebesta JA, Blackbourne LH, Herbert GS, Kauvar DS, Baer DG, et al: Prehospital tourniquet use in Operation Iraqi Freedom: effect on hemorrhage control and outcomes. J Trauma 64:S28-37; 2008

11. Belpomme V, Ricard-Hibon A, Devoir C, Dileseigres S, Devaud ML, Chollet C, et al: Correlation of arterial PCO2 and PETCO2 in prehospital controlled ventilation. Am J Emerg Med 23:852-859, 2005

12. Bickell WH, Stern S: Fluid replacement for hypotensive injury victims: how, when and what risks? Curr Opin Anaesthesiol 11:177-180, 1998

13. Bloch M: Cerebral effects of rewarming following prolonged hypothermia: significance for the management of severe cranio-cerebral injury and acute pyrexia. Brain 90:769-784, 1967

14. Bochicchio GV, Ilahi O, Joshi M, Bochicchio K, Scalea TM: Endotracheal intubation in the field does not improve outcome in trauma patients who present without an acutely lethal traumatic brain injury. J Trauma 54:307-311, 2003

15. Bouma GJ, Muizelaar JP: Cerebral blood flow, cerebral blood volume, and cerebrovascular reactivity after severe head injury. J Neurotrauma 9 (1 Suppl):S333-S348, 1992

16. Bouma GJ, Muizelaar JP, Stringer WA, Choi SC, Fatouros P, Young HF: Ultra-early evaluation of regional cerebral blood flow in severely head-injured patients using xenon-enhanced computerized tomography. J Neurosurg 77:360-368, 1992

17. Bourguignon PR, Shackford SR, Shiffer C, Nichols P, Nees 
AV: Delayed fluid resuscitation of head injury and uncontrolled hemorrhagic shock. Arch Surg 133:390-398, 1998

18. Brasel KJ, Bulger E, Cook AJ, Morrison LJ, Newgard CD, Tisherman SA, et al: Hypertonic resuscitation: design and implementation of a prehospital intervention trial. J Am Coll Surg 206:220-232, 2008

19. Bratton SL, Chestnut RM, Ghajar J, McConnell Hammond FF, Harris OA, Hartl R, et al: Guidelines for the management of severe traumatic brain injury. J Neurotrauma 24 (1 Suppl):S7-S95, 2007

20. Bratton SL, Chestnut RM, Ghajar J, McConnell Hammond FF, Harris OA, Hartl R, et al: Guidelines for the management of severe traumatic brain injury. I. Blood pressure and oxygenation. J Neurotrauma 24 (1 Suppl):S7-S13, 2007

21. Bratton SL, Chestnut RM, Ghajar J, McConnell Hammond FF, Harris OA, Hartl R, et al: Guidelines for the management of severe traumatic brain injury. II. Hyperosmolar therapy. J Neurotrauma 24 (1 Suppl):S14-S20, 2007

22. Bratton SL, Chestnut RM, Ghajar J, McConnell Hammond FF, Harris OA, Hartl R, et al: Guidelines for the management of severe traumatic brain injury. XIV. Hyperventilation. J Neurotrauma 24 (1 Suppl):S87-S90, 2007

23. Bullock MR, du Trevou MD, van Dellen JR, Nel JP, McKeown CP: Prevention of death from head injury in Natal. $\mathbf{S}$ Afr Med J 73:523-527, 1988

24. Burke AM, Quest DO, Chien S, Cerri C: The effects of mannitol on blood viscosity. J Neurosurg 55:550-553, 1981

25. Chan KH, Miller JD, Dearden NM: Intracranial blood flow velocity after head injury: relationship to severity of injury, time, neurological status and outcome. J Neurol Neurosurg Psychiatry 55:787-791, 1992

26. Chesnut RM, Marshall LF, Klauber MR, Blunt BA, Baldwin $\mathrm{N}$, Eisenberg HM, et al: The role of secondary brain injury in determining outcome from severe head injury. J Trauma 34:216-222, 1993

27. Chesnut RM, Marshall SB, Piek J, Blunt BA, Klauber MR, Marshall LF: Early and late systemic hypotension as a frequent and fundamental source of cerebral ischemia following severe brain injury in the Traumatic Coma Data Bank. Acta Neurochir Suppl (Wien) 59:121-125, 1993

28. Chi JH, Knudson MM, Vassar MJ, McCarthy MC, Shapiro MB, Mallet S, et al: Prehospital Hypoxia Affects Outcome in Patients With Traumatic Brain Injury: A Prospective Multicenter Study. J Trauma 61:1134-1141, 2006

29. Choi SC, Narayan RK, Anderson RL, Ward JD: Enhanced specificity of prognosis in severe head injury. J Neurosurg 69:381-385, 1988

30. Clifton GL, Miller ER, Choi SC, Levin HS, McCauley S, Smith KR Jr, et al: Hypothermia on admission in patients with severe brain injury. J Neurotrauma 19:293-301, 2002

31. Cooper DJ, Myles PS, McDermott FT, Murray LJ, Laidlaw J, Cooper G, et al: Prehospital hypertonic saline resuscitation of patients with hypotension and severe traumatic brain injury: a randomized controlled trial. JAMA 291:1350-1357, 2004

32. Cruz J, Minoja G, Okuchi K, Facco E: Successful use of the new high-dose mannitol treatment in patients with Glasgow Coma Scale scores of 3 and bilateral abnormal pupillary widening: a randomized trial. J Neurosurg 100:376-383, 2004

33. Davis DP: Prehospital intubation of brain-injured patients. Curr Opin Crit Care 14:142-148, 2008

34. Davis DP, Dunford JV, Ochs M, Park K, Hoyt DB: The use of quantitative end-tidal capnometry to avoid inadvertent severe hyperventilation in patients with head injury after paramedic rapid sequence intubation. J Trauma 56:808-814, 2004

35. Davis DP, Fakhry SM, Wang HE, Bulger EM, Domeier RM, Trask AL, et al: Paramedic rapid sequence intubation for severe traumatic brain injury: perspectives from an expert panel. Prehosp Emerg Care 11:1-8, 2007

36. Davis DP, Heister R, Poste JC, Hoyt DB, Ochs M, Dunford
JV: Ventilation patterns in patients with severe traumatic brain injury following paramedic rapid sequence intubation. Neurocrit Care 2:165-171, 2005

37. Davis DP, Hoyt DB, Ochs M, Fortlage D, Holbrook T, Marshall LK, et al: The effect of paramedic rapid sequence intubation on outcome in patients with severe traumatic brain injury. J Trauma 54:444-453, 2003

38. Davis DP, Hwang JQ, Dunford JV: Rate of decline in oxygen saturation at various pulse oximetry values with prehospital rapid sequence intubation. Prehosp Emerg Care 12:46-51, 2008

39. Davis DP, Kimbro TA, Vilke GM: The use of midazolam for prehospital rapid-sequence intubation may be associated with a dose-related increase in hypotension. Prehosp Emerg Care 5:163-168, 2001

40. Davis DP, Peay J, Serrano JA, Buono C, Vilke GM, Sise MJ, et al: The impact of aeromedical response to patients with moderate to severe traumatic brain injury. Ann Emerg Med 46:115-122, 2005

41. Davis DP, Peay J, Sise MJ, Vilke GM, Kennedy F, Eastman $\mathrm{AB}$, et al: The impact of prehospital endotracheal intubation on outcome in moderate to severe traumatic brain injury. $\mathbf{J}$ Trauma 58:933-939, 2005

42. Davis DP, Stern J, Sise MJ, Hoyt DB: A follow-up analysis of factors associated with head-injury mortality after paramedic rapid sequence intubation. J Trauma 59:486-490, 2005

43. Davis DP, Vadeboncoeur TF, Ochs M, Poste JC, Vilke GM, Hoyt DB: The association between field Glasgow Coma Scale score and outcome in patients undergoing paramedic rapid sequence intubation. J Emerg Med 29:391-397, 2005

44. Deakin C, Davies G: Defining trauma patient subpopulations for field stabilization. Eur J Emerg Med 1:31-33, 1994

45. Deane SA, Gaudry PL, Woods WP, Read CM, McNeil RJ: Interhospital transfer in the management of acute trauma. Aust N Z J Surg 60:441-446, 1990

46. Di Bartolomeo S, Sanson G, Nardi G, Scian F, Michelutto V, Lattuada L: Effects of 2 patterns of prehospital care on the outcome of patients with severe head injury. Arch Surg 136:1293-1300, 2001

47. Doberstein CE, Hovda DA, Becker DP: Clinical considerations in the reduction of secondary brain injury. Ann Emerg Med 22:993-997, 1993

48. Doyle JA, Davis DP, Hoyt DB: The use of hypertonic saline in the treatment of traumatic brain injury. J Trauma 50:367383, 2001

49. Dubick MA, Wade CE: A review of the efficacy and safety of $7.5 \% \mathrm{NaCl} / 6 \%$ dextran 70 in experimental animals and in humans. J Trauma 36:323-330, 1994

50. Duckrow RB, LaManna JC, Rosenthal M, Levasseur JE, Patterson JL Jr: Oxidative metabolic activity of cerebral cortex after fluid-percussion head injury in the cat. J Neurosurg 54:607-614, 1981

51. Dunford JV, Davis DP, Ochs M, Doney M, Hoyt DB: Incidence of transient hypoxia and pulse rate reactivity during paramedic rapid sequence intubation. Ann Emerg Med 42:721-728, 2003

52. Dunn LT: Secondary insults during the interhospital transfer of head-injured patients: an audit of transfers in the Mersey Region. Injury 28:427-431, 1997

53. Eckstein M, Chan L, Schneir A, Palmer R: Effect of prehospital advanced life support on outcomes of major trauma patients. J Trauma 48:643-648, 2000

54. Ellis DY, Davies GE, Pearn J, Lockey D: Prehospital rapidsequence intubation of patients with trauma with a Glasgow Coma Score of 13 or 14 and the subsequent incidence of intracranial pathology. Emerg Med J 24:139-141, 2007

55. Erecinska M, Thoresen M, Silver IA: Effects of hypothermia on energy metabolism in Mammalian central nervous system. J Cereb Blood Flow Metab 23:513-530, 2003 
56. Fearnside MR, Cook RJ, McDougall P, McNeil RJ: The Westmead Head Injury Project outcome in severe head injury. A comparative analysis of pre-hospital, clinical and CT variables. Br J Neurosurg 7:267-279, 1993

57. Freshman SP, Battistella FD, Matteucci M, Wisner DH: Hypertonic saline $(7.5 \%)$ versus mannitol: a comparison for treatment of acute head injuries. J Trauma 35:344-348, 1993

58. Fries D, Innerhofer P, Schobersberger W: Coagulation management in trauma patients. Curr Opin Anaesthesiol 15:217223, 2002

59. Gabriel EJ, Ghajar J, Jagoda A, Pons PT, Scalea T, Walters BC: Guidelines for prehospital management of traumatic brain injury. J Neurotrauma 19:111-174, 2002

60. Galarneau MR, Woodruff SI, Dye JL, Mohrle CR, Wade AL: Traumatic brain injury during Operation Iraqi Freedom: findings from the United States Navy-Marine Corps Combat Trauma Registry. J Neurosurg 108:950-957, 2008

61. Garner A, Crooks J, Lee A, Bishop R: Efficacy of prehospital critical care teams for severe blunt head injury in the Australian setting. Injury 32:455-460, 2001

62. Garner AA: The role of physician staffing of helicopter emergency medical services in prehospital trauma response. Emerg Med Australas 16:318-323, 2004

63. Garner AA, Schoettker P: Efficacy of pre-hospital interventions for the management of severe blunt head injury. Injury 33:329-337, 2002

64. Gentleman D: Causes and effects of systemic complications among severely head injured patients transferred to a neurosurgical unit. Int Surg 77:297-302, 1992

65. Gill MR, Reiley DG, Green SM: Interrater reliability of Glasgow Coma Scale scores in the emergency department. Ann Emerg Med 43:215-223, 2004

66. Graham DI, Ford I, Adams JH, Doyle D, Teasdale GM, Lawrence $\mathrm{AE}$, et al: Ischaemic brain damage is still common in fatal non-missile head injury. J Neurol Neurosurg Psychiatry 52:346-350, 1989

67. Guss DA, Meyer FT, Neuman TS, Baxt WG, Dunford JV Jr, Griffith LD, et al: The impact of a regionalized trauma system on trauma care in San Diego County. Ann Emerg Med 18:1141-1145, 1989

68. Haller JA Jr, Shorter N, Miller D, Colombani P, Hall J, Buck $\mathrm{J}$ : Organization and function of a regional pediatric trauma center: does a system of management improve outcome? J Trauma 23:691-696, 1983

69. Hannan EL, Farrell LS, Cooper A, Henry M, Simon B, Simon $\mathrm{R}$ : Physiologic trauma triage criteria in adult trauma patients: are they effective in saving lives by transporting patients to trauma centers? J Am Coll Surg 200:584-592, 2005

70. Hartl R, Gerber LM, Iacono L, Ni Q, Lyons K, Ghajar J: Direct transport within an organized state trauma system reduces mortality in patients with severe traumatic brain injury. $\mathbf{J}$ Trauma 60:1250-1256, 2006

71. Hartl R, Ghajar J, Hochleuthner H, Mauritz W: Hypertonic/ hyperoncotic saline reliably reduces ICP in severely headinjured patients with intracranial hypertension. Acta Neurochir Suppl 70:126-129, 1997

72. Haselsberger K, Pucher R, Auer LM: Prognosis after acute subdural or epidural haemorrhage. Acta Neurochir (Wien) 90:111-116, 1988

73. Helm M, Castner T, Lampl L: Environmental temperature stress on drugs in prehospital emergency medical service. Acta Anaesthesiol Scand 47:425-429, 2003

74. Helm M, Schuster R, Hauke J, Lampl L: Tight control of prehospital ventilation by capnography in major trauma victims. Br J Anaesth 90:327-332, 2003

75. Hunt J, Hill D, Besser M, West R, Roncal S: Outcome of patients with neurotrauma: the effect of a regionalized trauma system. Aust N Z J Surg 65:83-86, 1995
76. Jafar JJ, Johns LM, Mullan SF: The effect of mannitol on cerebral blood flow. J Neurosurg 64:754-759, 1986

77. Jenkins LW, Moszynski K, Lyeth BG, Lewelt W, DeWitt DS, Allen A, et al: Increased vulnerability of the mildly traumatized rat brain to cerebral ischemia: the use of controlled secondary ischemia as a research tool to identify common or different mechanisms contributing to mechanical and ischemic brain injury. Brain Res 477:211-224, 1989

78. Jennett B: Epidemiology of head injury. J Neurol Neurosurg Psychiatry 60:362-369, 1996

79. Johnson DL, Krishnamurthy S: Send severely head-injured children to a pediatric trauma center. Pediatr Neurosurg 25:309-314, 1996

80. Jurkovich GJ, Greiser WB, Luterman A, Curreri PW: Hypothermia in trauma victims: an ominous predictor of survival. J Trauma 27:1019-1024, 1987

81. Kaufmann MA, Buchmann B, Scheidegger D, Gratzl O, Radu EW: Severe head injury: should expected outcome influence resuscitation and first-day decisions? Resuscitation 23:199206, 1992

82. Klauber MR, Marshall LF, Toole BM, Knowlton SL, Bowers SA: Cause of decline in head-injury mortality rate in San Diego County, California. J Neurosurg 62:528-531, 1985

83. Kokoska ER, Smith GS, Pittman T, Weber TR: Early hypotension worsens neurological outcome in pediatric patients with moderately severe head trauma. J Pediatr Surg 33:333-338, 1998

84. Lee A, Garner A, Fearnside M, Harrison K: Level of prehospital care and risk of mortality in patients with and without severe blunt head injury. Injury 34:815-819, 2003

85. Lerner EB, Moscati RM: The golden hour: scientific fact or medical "urban legend"? Acad Emerg Med 8:758-760, 2001

86. Lewelt W, Jenkins LW, Miller JD: Effects of experimental fluid-percussion injury of the brain on cerebrovascular reactivity of hypoxia and to hypercapnia. J Neurosurg 56:332-338, 1982

87. Liberman M, Mulder D, Sampalis J: Advanced or basic life support for trauma: meta-analysis and critical review of the literature. J Trauma 49:584-599, 2000

88. Lokkeberg AR, Grimes RM: Assessing the influence of nontreatment variables in a study of outcome from severe head injuries. J Neurosurg 61:254-262, 1984

89. Luna GK, Maier RV, Pavlin EG, Anardi D, Copass MK, Oreskovich MR: Incidence and effect of hypothermia in seriously injured patients. J Trauma 27:1014-1018, 1987

90. Mackenzie CF: Threats and opportunities in pre-hospital management of traumatic brain injury. J Neurosurg Anesthesiol 16:70-74, 2004

91. MacKenzie EJ, Rivara FP, Jurkovich GJ, Nathens AB, Frey KP, Egleston BL, et al: A national evaluation of the effect of trauma-center care on mortality. N Engl J Med 354:366-378, 2006

92. Manley G, Knudson MM, Morabito D, Damron S, Erickson V, Pitts L: Hypotension, hypoxia, and head injury: frequency, duration, and consequences. Arch Surg 136:1118-1123, 2001

93. Manley GT, Hemphill JC, Morabito D, Derugin N, Erickson V, Pitts LH, et al: Cerebral oxygenation during hemorrhagic shock: perils of hyperventilation and the therapeutic potential of hypoventilation. J Trauma 48:1025-1032, 2000

94. Marion DW, Carlier PM: Problems with initial Glasgow Coma Scale assessment caused by prehospital treatment of patients with head injuries: results of a national survey. J Trauma 36:89-95, 1994

95. Marion DW, Darby J, Yonas H: Acute regional cerebral blood flow changes caused by severe head injuries. J Neurosurg 74:407-414, 1991

96. Marion DW, Puccio A, Wisniewski SR, Kochanek P, Dixon CE, Bullian L, et al: Effect of hyperventilation on extracellular 
concentrations of glutamate, lactate, pyruvate, and local cerebral blood flow in patients with severe traumatic brain injury. Crit Care Med 30:2619-2625, 2002

97. Marmarou A, Lu J, Butcher I, McHugh GS, Murray GD, Steyerberg EW, et al: Prognostic value of the Glasgow Coma Scale and pupil reactivity in traumatic brain injury assessed pre-hospital and on enrollment: an IMPACT analysis. J Neurotrauma 24:270-280, 2007

98. Marshall LF, Barba D, Toole BM, Bowers SA: The oval pupil: clinical significance and relationship to intracranial hypertension. J Neurosurg 58:566-568, 1983

99. Martin NA, Patwardhan RV, Alexander MJ, Africk CZ, Lee JH, Shalmon E, et al: Characterization of cerebral hemodynamic phases following severe head trauma: hypoperfusion, hyperemia, and vasospasm. J Neurosurg 87:9-19, 1997

100. McConnell KJ, Newgard CD, Mullins RJ, Arthur M, Hedges JR: Mortality benefit of transfer to level I versus level II trauma centers for head-injured patients. Health Serv Res 40:435-457, 2005

101. McDowall DG: Interrelationships between blood oxygen tensions and cerebral blood flow. Int Anesthesiol Clin 4:205-219, 1966

102. McHugh GS, Engel DC, Butcher I, Steyerberg EW, Lu J, Mushkudiani N, et al: Prognostic value of secondary insults in traumatic brain injury: results from the IMPACT study. $\mathbf{J}$ Neurotrauma 24:287-293, 2007

103. Miller JD: Assessing patients with head injury. Br J Surg 77:241-242, 1990

104. Miller JD, Sweet RC, Narayan R, Becker DP: Early insults to the injured brain. JAMA 240:439-442, 1978

105. Muhm JM, Rock PB, McMullin DL, Jones SP, Lu IL, Eilers KD, et al: Effect of aircraft-cabin altitude on passenger discomfort. $\mathbf{N}$ Engl J Med 357:18-27, 2007

106. Muizelaar JP, Lutz HA 3rd, Becker DP: Effect of mannitol on ICP and CBF and correlation with pressure autoregulation in severely head-injured patients. J Neurosurg 61:700-706, 1984

107. Muizelaar JP, Marmarou A, Ward JD, Kontos HA, Choi SC, Becker DP, et al: Adverse effects of prolonged hyperventilation in patients with severe head injury: a randomized clinical trial. J Neurosurg 75:731-739, 1991

108. Muizelaar JP, Wei EP, Kontos HA, Becker DP: Mannitol causes compensatory cerebral vasoconstriction and vasodilation in response to blood viscosity changes. J Neurosurg 59:822-828, 1983

109. Munar F, Ferrer AM, de Nadal M, Poca MA, Pedraza S, Sahuquillo J, et al: Cerebral hemodynamic effects of $7.2 \%$ hypertonic saline in patients with head injury and raised intracranial pressure. J Neurotrauma 17:41-51, 2000

110. Murray JA, Demetriades D, Berne TV, Stratton SJ, Cryer HG, Bongard F, et al: Prehospital intubation in patients with severe head injury. J Trauma 49:1065-1070, 2000

111. Obrist WD, Langfitt TW, Jaggi JL, Cruz J, Gennarelli TA: Cerebral blood flow and metabolism in comatose patients with acute head injury. Relationship to intracranial hypertension. J Neurosurg 61:241-253, 1984

112. Ogden AT, Mayer SA, Connolly ES Jr: Hyperosmolar agents in neurosurgical practice: the evolving role of hypertonic saline. Neurosurgery 57:207-215, 2005

113. Oppe S, De Charro FT: The effect of medical care by a helicopter trauma team on the probability of survival and the quality of life of hospitalised victims. Accid Anal Prev 33:129-138, 2001

114. Ostensen J, Stokke ES, Bugge JF, Langberg H, Kiil F: Difference between hypertonic $\mathrm{NaCl}$ and $\mathrm{NaHCO} 3$ as osmotic diuretics in dog kidneys. Acta Physiol Scand 137:177-187, 1989

115. Osterwalder JJ: Mortality of blunt polytrauma: a comparison between emergency physicians and emergency medical technicians-prospective cohort study at a level I hospital in eastern Switzerland. J Trauma 55:355-361, 2003

116. Overgaard J, Mosdal C, Tweed WA: Cerebral circulation after head injury. Part 3: Does reduced regional cerebral blood flow determine recovery of brain function after blunt head injury? J Neurosurg 55:63-74, 1981

117. Owens TM, Watson WC, Prough DS, Uchida T, Kramer GC: Limiting initial resuscitation of uncontrolled hemorrhage reduces internal bleeding and subsequent volume requirements. J Trauma 39:200-209, 1995

118. Pauldine R, Beck G, Salinas J, Kaczka DW: Closed-loop strategies for patient care systems. J Trauma 64:S289-S294, 2008

119. Peterson K, Carson S, Carney N: Hypothermia treatment for traumatic brain injury: a systematic review and meta-analysis. J Neurotrauma 25:62-71, 2008

120. Piek J, Chesnut RM, Marshall LF, van Berkum-Clark M, Klauber MR, Blunt BA, et al: Extracranial complications of severe head injury. J Neurosurg 77:901-907, 1992

121. Poon WS, Li AK: Comparison of management outcome of primary and secondary referred patients with traumatic extradural haematoma in a neurosurgical unit. Injury 22:323-325, 1991

122. Poste JC, Davis DP, Ochs M, Vilke GM, Castillo EM, Stern $\mathrm{J}$, et al: Air medical transport of severely head-injured patients undergoing paramedic rapid sequence intubation. Air Med J 23:36-40, 2004

123. Potoka DA, Schall LC, Gardner MJ, Stafford PW, Peitzman AB, Ford HR: Impact of pediatric trauma centers on mortality in a statewide system. J Trauma 49:237-245, 2000

124. Rosner MJ, Daughton S: Cerebral perfusion pressure management in head injury. J Trauma 30:933-940, 1990

125. Rosner MJ, Rosner SD, Johnson AH: Cerebral perfusion pressure: management protocol and clinical results. J Neurosurg 83:949-962, 1995

126. Rosomoff HL, Holaday DA: Cerebral blood flow and cerebral oxygen consumption during hypothermia. Am J Physiol 179:85-88, 1954

127. Roy PD: The value of trauma centres: a methodologic review. Can J Surg 30:17-22, 1987

128. Rudehill A, Bellander BM, Weitzberg E, Bredbacka S, Backheden M, Gordon E: Outcome of traumatic brain injuries in 1,508 patients: impact of prehospital care. J Neurotrauma 19:855-868, 2002

129. Rutland-Brown W, Langlois JA, Nicaj L, Thomas RG Jr, Wilt SA, Bazarian JJ: Traumatic brain injuries after mass-casualty incidents: lessons from the 11 September 2001 World Trade Center attacks. Prehospital Disaster Med 22:157-164, 2007

130. Sampalis JS, Denis R, Frechette P, Brown R, Fleiszer D, Mulder D: Direct transport to tertiary trauma centers versus transfer from lower level facilities: impact on mortality and morbidity among patients with major trauma. J Trauma 43:288-296, 1997

131. Sampalis JS, Tamim H, Denis R, Boukas S, Ruest SA, Nikolis A, et al: Ineffectiveness of on-site intravenous lines: is prehospital time the culprit? J Trauma 43:608-617, 1997

132. Schreiber MA, Aoki N, Scott BG, Beck JR: Determinants of mortality in patients with severe blunt head injury. Arch Surg 137:285-290, 2002

133. Seelig JM, Becker DP, Miller JD, Greenberg RP, Ward JD, Choi SC: Traumatic acute subdural hematoma: major mortality reduction in comatose patients treated within four hours. N Engl J Med 304:1511-1518, 1981

134. Seguin P, Bleichner JP, Branger B, Guillou YM, Feuillu A, Malledant Y: [The measurement of end-tidal carbon dioxide (PETCO2) is not a significant parameter to monitor in patients with severe traumatic brain injury.] Can J Anaesth 48:396-400, 2001 (Fr)

135. Servadei F, Nasi MT, Cremonini AM, Giuliani G, Cenni P, Nanni A: Importance of a reliable admission Glasgow Coma Scale score for determining the need for evacuation of posttraumatic subdural hematomas: a prospective study of 65 patients. J Trauma 44:868-873, 1998

136. Shackford SR, Mackersie RC, Hoyt DB, Baxt WG, Eastman AB, Hammill FN, et al: Impact of a trauma system on outcome of 
severely injured patients. Arch Surg 122:523-527, 1987

137. Sheinberg M, Kanter MJ, Robertson CS, Contant CF, Narayan RK, Grossman RG: Continuous monitoring of jugular venous oxygen saturation in head-injured patients. J Neurosurg 76:212-217, 1992

138. Siesjo BK: Cerebral circulation and metabolism. J Neurosurg 60:883-908, 1984

139. Slovis CM, Herr EW, Londorf D, Little TD, Alexander BR, Guthmann RJ: Success rates for initiation of intravenous therapy en route by prehospital care providers. Am J Emerg Med 8:305-307, 1990

140. Smith JS Jr, Martin LF, Young WW, Macioce DP: Do trauma centers improve outcome over non-trauma centers: the evaluation of regional trauma care using discharge abstract data and patient management categories. J Trauma 30:1533-1538, 1990

141. Smith RF, Frateschi L, Sloan EP, Campbell L, Krieg R, Edwards LC, et al: The impact of volume on outcome in seriously injured trauma patients: two years' experience of the Chicago Trauma System. J Trauma 30:1066-1066, 1990

142. Sorani MD, Manley GT: Dose-response relationship of mannitol and intracranial pressure: a metaanalysis. J Neurosurg 108:80-87, 2008

143. Stocchetti N, Furlan A, Volta F: Hypoxemia and arterial hypotension at the accident scene in head injury. J Trauma 40:764-767, 1996

144. Stone JL, Lowe RJ, Jonasson O, Baker RJ, Barrett J, Oldershaw $\mathrm{JB}$, et al: Acute subdural hematoma: direct admission to a trauma center yields improved results. J Trauma 26:445-450, 1986

145. Suarez JI, Qureshi AI, Bhardwaj A, Williams MA, Schnitzer MS, Mirski M, et al: Treatment of refractory intracranial hypertension with 23.4\% saline. Crit Care Med 26:1118-1122, 1998

146. The Brain Truama Foudation: Guidelines for prehospital management of traumatic brain injury, 2nd Edition. Prehosp Emerg Care 12 (Suppl):S1-S52, 2007

147. Thomas SH, Orf J, Wedel SK, Conn AK: Hyperventilation in traumatic brain injury patients: inconsistency between consensus guidelines and clinical practice. J Trauma 52:47-53, 2002

148. Thurman DJ: The epidemiology and economics of head trauma, in Miller L, Hayes R (eds): Head Trauma: Basic, preclinical, and clinical directions. New York: Wiley, 2001, pp 327-347

149. Trunkey D: Towards optimal trauma care. Arch Emerg Med 2:181-195, 1985

150. Vassar MJ, Fischer RP, O’Brien PE, Bachulis BL, Chambers JA, Hoyt DB, et al: A multicenter trial for resuscitation of injured patients with $7.5 \%$ sodium chloride. The effect of added dextran 70. The Multicenter Group for the Study of Hypertonic Saline in Trauma Patients. Arch Surg 128:1003-1013, 1993

151. Vassar MJ, Perry CA, Gannaway WL, Holcroft JW: $7.5 \%$ sodium chloride/dextran for resuscitation of trauma patients undergoing helicopter transport. Arch Surg 126:1065-1072, 1991
152. Vassar MJ, Perry CA, Holcroft JW: Prehospital resuscitation of hypotensive trauma patients with $7.5 \% \mathrm{NaCl}$ versus $7.5 \% \mathrm{NaCl}$ with added dextran: a controlled trial. J Trauma 34:622-623, 1993

153. Vialet R, Albanese J, Thomachot L, Antonini F, Bourgouin A, Alliez B, et al: Isovolume hypertonic solutes (sodium chloride or mannitol) in the treatment of refractory posttraumatic intracranial hypertension: $2 \mathrm{~mL} / \mathrm{kg} \mathrm{7.5 \%} \mathrm{saline} \mathrm{is} \mathrm{more} \mathrm{effective} \mathrm{than} 2 \mathrm{~mL} /$ kg 20\% mannitol. Crit Care Med 31:1683-1687, 2003

154. Vincent JL, Berre J: Primer on medical management of severe brain injury. Crit Care Med 33:1392-1399, 2005

155. Wade CE, Grady JJ, Kramer GC, Younes RN, Gehlsen K, Holcroft JW: Individual patient cohort analysis of the efficacy of hypertonic saline/dextran in patients with traumatic brain injury and hypotension. J Trauma 42:S61-S65, 1997

156. Wald SL, Shackford SR, Fenwick J: The effect of secondary insults on mortality and long-term disability after severe head injury in a rural region without a trauma system. J Trauma 34:377-382, 1993

157. Wang HE, Callaway CW, Peitzman AB, Tisherman SA: Admission hypothermia and outcome after major trauma. Crit Care Med 33:1296-1301, 2005

158. Wang HE, Peitzman AB, Cassidy LD, Adelson PD, Yealy DM: Out-of-hospital endotracheal intubation and outcome after traumatic brain injury. Ann Emerg Med 44:439-450, 2004

159. Warner KJ, Cuschieri J, Copass MK, Jurkovich GJ, Bulger EM: Emergency department ventilation effects outcome in severe traumatic brain injury. J Trauma 64:341-347, 2008

160. Watts DD, Hanfling D, Waller MA, Gilmore C, Fakhry SM, Trask AL: An evaluation of the use of guidelines in prehospital management of brain injury. Prehosp Emerg Care 8:254-261, 2004

161. Wise BL, Chater N: The value of hypertonic mannitol solution in decreasing brain mass and lowering cerebro-spinal-fluid pressure. J Neurosurg 19:1038-1043, 1962

162. Worthley LI, Cooper DJ, Jones N: Treatment of resistant intracranial hypertension with hypertonic saline. Report of two cases. J Neurosurg 68:478-481, 1988

163. Wright KD, Knowles CH, Coats TJ, Sutcliffe JC: 'Efficient' timely evacuation of intracranial haematoma-the effect of transport direct to a specialist centre. Injury 27:719-721, 1996

Manuscript submitted June 16, 2008.

Accepted August 29, 2008.

Address correspondence to: Shirley I. Stiver, M.D., Ph.D. Department of Neurosurgery, University of California San Francisco 1001 Potrero Ave, Bldg. 1, Rm. 101, San Francisco, California 94110-0899. email: sstiver@neurosurg.ucsf.edu. 